\title{
Article \\ CD14 Is Involved in the Interferon Response of Human Macrophages to Rubella Virus Infection
}

\author{
Erik Schilling ${ }^{1}$, Lukas Pfeiffer ${ }^{2}$, Sunna Hauschildt ${ }^{3,4}$, Ulrike Koehl ${ }^{1,4,5}$ and Claudia Claus ${ }^{2, * \text { (D) }}$ \\ 1 Institute of Clinical Immunology, Medical Faculty, Leipzig University, Johannisallee 30, \\ 04103 Leipzig, Germany; erik.schilling@medizin.uni-leipzig.de (E.S.) \\ Ulrike.Koehl@medizin.uni-leipzig.de (U.K.) \\ 2 Institute of Medical Microbiology and Virology, Medical Faculty, Leipzig University, Johannisallee 30, \\ 04103 Leipzig, Germany; lukaspfeiffer05@gmail.com \\ 3 Institute of Biology, Faculty of Life Sciences, Leipzig University, Talstrasse 33, 04103 Leipzig, Germany; \\ shaus@rz.uni-leipzig.de \\ 4 Fraunhofer Institute for Cell Therapy and Immunology, 04103 Leipzig, Germany \\ 5 Institute for Cellular Therapeutics, Hannover Medical School, 30625 Hannover, Germany \\ * Correspondence: claudia.claus@medizin.uni-leipzig.de; Tel.: +49-341-9714321
}

check for

updates

Citation: Schilling, E.; Pfeiffer, L.; Hauschildt, S.; Koehl, U.; Claus, C. CD14 Is Involved in the Interferon Response of Human Macrophages to Rubella Virus Infection. Biomedicines 2022, 10, 266. https://doi.org/ 10.3390/biomedicines10020266

Academic Editors: Alexei Gratchev, Alexander N. Orekhov and Evgeny E. Bezsonov

Received: 21 December 2021

Accepted: 19 January 2022

Published: 26 January 2022

Publisher's Note: MDPI stays neutral with regard to jurisdictional claims in published maps and institutional affiliations.

Copyright: (C) 2022 by the authors. Licensee MDPI, Basel, Switzerland. This article is an open access article distributed under the terms and conditions of the Creative Commons Attribution (CC BY) license (https:// creativecommons.org/licenses/by/ $4.0 /)$.

\begin{abstract}
Macrophages (MФ) as specialized immune cells are involved in rubella virus (RuV) pathogenesis and enable the study of its interaction with the innate immune system. A similar replication kinetics of $\mathrm{RuV}$ in the two human $\mathrm{M} \Phi$ types, the pro-inflammatory M1-like (or GM-M $\Phi$ ) and anti-inflammatory M2-like (M-M $\Phi)$, was especially in M-M $\Phi$ accompanied by a reduction in the expression of the innate immune receptor CD14. Similar to RuV infection, exogenous interferon (IFN) $\beta$ induced a loss of glycolytic reserve in $\mathrm{M}-\mathrm{M} \Phi$, but in contrast to $\mathrm{RuV}$ no noticeable influence on CD14 expression was detected. We next tested the contribution of CD14 to the generation of cytokines/chemokines during RuV infection of M-M $\Phi$ through the application of anti-CD14 blocking antibodies. Blockage of CD14 prior to RuV infection enhanced generation of virus progeny. In agreement with this observation, the expression of IFNs was significantly reduced in comparison to the isotype control. Additionally, the expression of TNF- $\alpha$ was slightly reduced, whereas the chemokine CXCL10 was not altered. In conclusion, the observed downmodulation of CD14 during $\mathrm{RuV}$ infection of M-M $\Phi$ appears to contribute to virus-host-adaptation through a reduction of the IFN response.
\end{abstract}

Keywords: chemokine; cytokine; extracellular flux analysis; glycolysis

\section{Introduction}

The innate immune response is an important first line of defence against virus infections and a regulatory component for the adaptive immune response. As one of its cellular components, macrophages $(\mathrm{M} \Phi)$ fulfil a broad range of functions and are present in multiple tissues and organs. The $\mathrm{M} \Phi$ population in the body comprises mature tissue $\mathrm{M} \Phi$ besides M $\Phi$ that are differentiated from monocytes, which are generated by haematopoietic stem cells in the bone marrow and released into the blood circulation [1]. Depending on their tissue environment and the respective tissue-derived signals $M \Phi$ can undergo classical (M1) or alternate (M2) polarization including intermediate subtypes [2]. The polarization state comprises differences in their functionalities and reliance on metabolic pathways: M1 M $\Phi$ are destructive on their surrounding tissue and rely mainly on glycolysis, whereas anti-inflammatory $\mathrm{M} 2 \mathrm{M} \Phi$ function in tissue re-modelling and wound-healing and utilize mainly mitochondrial respiration $[1,3]$. However, based on these tissue-protective functions M2 M $\Phi$ also enable persistence of some pathogens in the respective tissue [4]. Such a close association of M2 MФ with virus persistence applies to rubella virus $(\mathrm{RuV})$ as a member of the family Matonaviridae. Under some immune privileged conditions reactivation of the 
vaccine strain of this single-stranded RNA virus with a genome in positive polarity can occur [5]. There is an association between $\mathrm{RuV}$ and $\mathrm{M} \Phi$ as these cells play an important role in the replication and spread of $\mathrm{RuV}$ and as such in rubella pathogenesis. In line with this, van der Logt et al. showed in an early work that monocyte-derived M $\Phi$ support $\mathrm{RuV}$ replication [6]. Furthermore, the results of Lazar et al. revealed that in tissue samples from patients with fatal congenital rubella syndrome (CRS) mainly alveolar M $\Phi$ were positive for RuV antigen [7]. In our previous work we demonstrated that both human GM-M $\Phi$ and human $\mathrm{M}-\mathrm{M} \Phi$ were infected with $\mathrm{RuV}$ and replication of $\mathrm{RuV}$ occured at a similar rate in both cell types [8]. RuV infects only humans and until 2020 no close relatives of RuV among animal and human viruses were known. Through metagenomic analysis ruhugu and rustrela virus were identified in different animal species including bats and rodents [9]. The high sequence similarity between $\mathrm{RuV}$ and ruhugu and rustrela virus highlights their potential as emerging pathogens with the possibility of transmission to humans [9]. In addition to the discovery of its close relatives, an association of $\mathrm{RuV}$ with granulomas in patients with primary immunodeficiencies (PIDs) [10] re-emphasizes the importance of research into the interaction of $\mathrm{RuV}$ with immune cells. The $\mathrm{RuV}$ vaccine RA27/3 was licensed in 1969 and is safe and very efficient with long lasting immunity [11]. However, in recent years a close correlation between reactivated $\mathrm{RuV}$ vaccine with granulomas in PID patients was shown [10]. Within these granulomas, $\mathrm{RuV}$ antigen was mainly identified in keratinocytes and M2 M patients suggests its low cytopathogenic impact along with the possibility of adaptation to antiviral mechanisms.

The functional state of $M \Phi$ can be directed by multiple factors. Among those the monocyte differentiation antigen CD14 serves as an innate immune receptor and fulfils several functions. CD14 promotes inflammation and its expression on tumour-associated immune cells influences tumour immunosurveillance [12]. Moreover, CD14 functions as a pattern recognition receptor (PRR) and as a co-receptor for several toll-like receptors (TLRs) [13]. Ligands of CD14 comprise not only bacterial and viral pathogen-associated molecular patterns (PAMPs), but also endogenous molecules. The release of heat shock protein 70 (HSP70) activates pro-inflammatory signals in a CD14-dependent manner [14]. As an example for a bacterial PAMP, CD14 binds lipopolysaccharide (LPS) from gramnegative bacteria and transfers it to TLR4 $[15,16]$. Among viral PAMPs recognized by CD14 are the fusion protein of respiratory syncytial virus and components of cytomegalovirus (CMV) particles in association with TLR4 and TLR2, respectively $[17,18]$.

Here we addressed the involvement of CD14 in RuV-induced innate immune response in M1- and M2-like human M $\Phi$, which can both be productively infected by RuV [19]. The

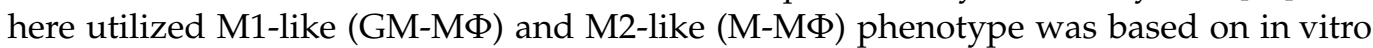
differentiation of PBMC-derived monocytes in the presence of GM-CSF and M-CSF, respectively. After RuV infection, a reduction of CD14 occurred in both M $\Phi$ types at mRNA and protein level, which was especially prominent in M-M $\Phi$. The application of exogenous interferon (IFN)- $\beta$ indicated that this reduction was not related to the $\mathrm{RuV}$ infection-induced IFN response. However, the application of extracellular flux analysis together with a glycolysis stress test revealed that the loss of glycolytic capacity noted after RuV infection was also induced by exogenous IFN- $\beta$. As a mimetic of the reduced CD14 expression level during $\mathrm{RuV}$ infection, we added anti-CD14 blocking antibodies prior to RuV infection. In comparison to the isotype control, blockage of CD14 increased the amount of extracellular virus particles and altered specific components of the cytokine/chemokine profile after infection with RuV: type I and III IFNs were significantly and TNF- $\alpha$ was slightly reduced, whereas CXCL10 (IP-10) was not affected. With our study we highlight that CD14 is involved in the immune response of $\mathrm{M} \Phi$ against $\mathrm{RuV}$. The $\mathrm{RuV}$ infection-associated reduction in CD14 expression could support its course of infection in $M \Phi$ and potentially contribute to the in vivo persistence of $\mathrm{RuV}$ in $\mathrm{M} 2 \mathrm{M} \Phi$. 


\section{Materials and Methods}

\subsection{Reagents and Antibodies}

CD14 blocking antibody (Ab) (MEM-18) and the corresponding mouse IgG1 isotype control Ab (MOPC-21) were obtained from EXBIO Praha (Vestec, Czech Republic). Recombinant human IFN- $\beta$ was purchased from Peprotech (Hamburg, Germany).

\subsection{Cell Separation and Cell Culture}

Human peripheral blood mononuclear cells from buffy coats of healthy donors (blood service, Institute of Transfusion Medicine University Hospital Leipzig; ethics license 272-1213082012) were isolated using a Ficoll-Paque Plus (GE Healthcare, Little Chalfont, Buckinghamshire, UK) centrifugation step. Following a washing step with PBS containing $0.3 \mathrm{mM}$ EDTA, monocytes were isolated by counter-flow elutriation using the JE-5.0 elutriation system (Beckman Coulter, Brea, CA, USA), as described previously [20].

The purity of isolated monocytes was determined by staining of CD14 surface marker with anti-CD14-APC mouse Ab (M5E2, BioLegend, San Diego, CA, USA) followed by flow cytometry analysis. Monocyte fractions with a purity of at least $90 \%$ were suspended $\left(5 \times 10^{5}\right.$ cells $\left./ \mathrm{mL}\right)$ in RPMI 1640 medium supplemented with $10 \%(v / v)$ fetal calf serum (FCS, Sigma-Aldrich, Taufkirchen, Germany), $100 \mathrm{U} / \mathrm{mL}$ penicillin and $100 \mathrm{mg} / \mathrm{mL}$ streptomycin (both from Seromed Biochrom KG, Berlin, Germany). Differentiation into M $\Phi$ was induced by adding $500 \mathrm{IU} / \mathrm{mL}$ GM-CSF (Leukine, sargramostim) (GM-MФ) or $50 \mathrm{ng} / \mathrm{mL}$ M-CSF (R\&D Systems, Minneapolis, MO, USA) (M-MФ). After 7 days of incubation at $37^{\circ} \mathrm{C}$ and $5 \% \mathrm{CO}_{2}$ in teflon bags (Zell-Kontakt, Nörte-Hardenberg, Germany; fluorinated ethylene propylene foil, $50 \mu \mathrm{m}$, hydrophobic), M $\Phi$ were harvested and counted. Prior to use in experiments, M $\left(5 \times 10^{5}\right.$ cells $\left./ \mathrm{mL}\right)$ were suspended in RPMI 1640 medium (with L-glutamine, $25 \mathrm{mM}$ HEPES and phenol red, GE Healthcare (Little Chalfont, Buckinghamshire, UK) supplemented with 10\% (v/v) FCS, $100 \mathrm{U} / \mathrm{mL}$ penicillin and $100 \mathrm{mg} / \mathrm{mL}$ streptomycin and plated followed by incubation for $2 \mathrm{~h}$ in cell culture plates.

\subsection{Flow Cytometry Analysis}

Flow cytometry analysis of markers expressed at the surface of $M \Phi$ was performed with direct dye labelled antibodies anti-CD14-APC mouse Ab (M5E2, BioLegend), antiCD40-PerCp mouse Ab (Elabscience Biotechnology, Houston, TX, USA), anti-CD80-PE mouse Ab (L307, BD Pharmingen, San Jose, CA, USA), anti-CD86-pacific blue mouse Ab (IT2.2, BioLegend) and the respective isotype controls as described previously [21].

\subsection{Virus Infections of $M \Phi$}

Infection of M $\Phi$ with RuV (in agreement with ethics license 001/19-ek) was carried out with the low-passaged (up to passage 10) clinical isolate RVi/Wuerzburg.DEU/47.11_1200009 (Wb-12). RuV was generated on epithelial Vero cells (green monkey kidney, ATCC CCL-81). Dulbecco's modified Eagle's medium (DMEM; Thermo Fisher Scientific, Waltham, MA, USA) supplemented with 10\% FCS was used for cultivation of Vero cells. As titered on Vero cells by standard plaque assay for $\mathrm{RuV}$, human $\mathrm{M} \Phi$ were infected at an MOI of 1.5 if not indicated otherwise. As a control, $\mathrm{RuV}$ was inactivated by UV-light with $900,000 \mu \mathrm{J} / \mathrm{cm}^{2}$ (UV-Stratalinker 2000, Stratagene, San Diego, CA, USA). Before infection with virus stock solution, the culture media was discarded. After $2 \mathrm{~h}$ virus stock was removed and fresh culture media was added after one washing step with PBS.

\subsection{Immunofluorescence Microscopy and Apoptosis Assessment}

The immunofluorescence analysis of $\mathrm{RuV}$-infected $\mathrm{M} \Phi$ using monoclonal antibody against RuV capsid protein (clone 2-36, Meridian Life Science, Inc., Memphis, TN, USA) was performed as described previously [8]. For apoptotic assessment the CellEvent Caspase3/7 Green Detection Reagent (Invitrogen, Thermo Fisher Scientific). Cleavage of the DEVD peptide by activated caspase $3 / 7$ results in release of the conjugated nucleic acid-binding 
dye. Upon cleavage the dye becomes fluorescent and can be detected in the nucleus. The proportion of fluorescent nuclei was determined by fluorescent microscopy.

\subsection{Measurement of Cytokines/Chemokines in Culture Supernatants}

TNF- $\alpha$ and IFNs were determined in culture supernatants of M $\Phi\left(5 \times 10^{5} / \mathrm{mL}\right)$ using a customized version of LEGENDPLEX human type 1/2/3 Interferon panel (5-plex) kit in combination with human TNF- $\alpha$ beads B3 (BioLegend) according to the manufacturer's protocol. CXCL10 protein in culture supernatants of M $\Phi\left(5 \times 10^{5} / \mathrm{mL}\right)$ was measured using a human CXCL10 ELISA kit (R\&D Systems, Minneapolis, MN, USA) according to the manufacturer's protocol.

\subsection{Western Blot}

Analysis of protein expression by Western blot was performed as described previously [8]. Briefly, the following antibodies were used at indicated dilutions for the detection of proteins on PVDF membranes: anti-CD14 mouse Ab (D7A2T, 1:1000); anti-RuV (E1) mouse Ab (1:500, Merck, Darmstadt, Germany); anti-phospho-Stat-1 rabbit Ab (Tyr701, D4A7, 1:1000) and anti- $\beta$-actin mouse Ab (AC 74, 1:2000, Sigma-Aldrich, St. Louis, MO, USA). The POD-conjugated secondary antibodies goat anti-rabbit IgG Ab (1:20,000, Dianova, Hamburg, Germany) or goat anti-mouse IgG Ab (1:8000, Sigma-Aldrich, St. Louis, $\mathrm{MO}$, USA) were used for the detection of the respective primary antibodies.

\subsection{RNA Isolation and Reverse Transcription}

The RNeasy Mini Kit (Qiagen, Hilden, Germany) was used according to the manufacturer's protocol for total RNA extraction from $M \Phi\left(3 \times 10^{5}\right)$ after washing with PBS and including DNase I treatment. Reverse transcription of equal amounts of RNA (250 ng) to cDNA was performed as previously described [20].

\subsection{Real-Time PCR ( $q P C R)$}

Real-time PCR was carried out as described previously [8] with the following primers: GNB2L1 (Forward 5'-GAGTGTGGCCTTCTCCTCTG-3'; Reverse 5'-GCTTGCAGTTAGCCA GGTTC-3') [22], IFN- $\beta$ (Forward 5'-AACTTTGACATCCCTGAGGAGATTAAGCAG-3'; Reverse $5^{\prime}$-GACTATGGTCCAGGCACAGTGACTGTACTC-3') [23], IFN- $\lambda 1$ (Forward 5'GCAGGTTCAAATCTCTGTCACC-3'; Reverse 5'-AAGACAGGAGAGCTGCAACTC-3') [24], TNF- $\alpha$ (Forward $5^{\prime}$-TCAGCCTCTTCTCCTTCCTG-3'; Reverse $5^{\prime}$-GGCTACAGGCTTGTCACTCG-3') [25], CD14 (Forward 5'-GCCGCTGTGTAGGAAAGAAG-3'; Reverse 5'-GCTGAGGTTCGGAGAAGTTG-3') [26], CXCL10 (Forward 5'-CCATTCTGATTTGCTGCCTTA-3'; Reverse 5'-TGATGCAGGTACAGCGTACAG-3') [27].

\subsection{Metabolic Assessment of the Extracellular Acidification Rate (ECAR) through Extracellular Flux Analysis}

Extracellular flux measurement was carried out with an XFp analyser (Agilent Seahorse Technologies, Santa Clara, CA, USA). XFp Seahorse plates were seeded with M $\Phi$ at a density of $4 \times 10^{4}$ cells per well. Before measurement culture medium was replaced by XF base medium (Agilent Seahorse Technologies) supplemented with $2 \mathrm{mM}$ glutamine. The glycolysis stress test kit (Agilent Seahorse Technologies) was carried out as described by the manufacturer. As exemplified in Supplementary Figure S1, 12 measurement points covered successive injection of glucose, oligomycin $(1 \mu \mathrm{M})$ and 2-deoxy-glucose.

\subsection{Statistical Analysis}

Data are shown as the mean \pm standard deviation (SD). All statistical analyses were carried out using the SigmaPlot ${ }^{\circledR}$ software. Statistical significance was calculated with Student's $t$-test or ANOVA test. 


\section{Results}

\subsection{The Initial Infectious Dose Has a Slight Influence on RuV Infection in GM- and M-MФ}

In our previous study, we examined the response of $M \Phi$ to $\mathrm{RuV}$ through the application of just one infectious dose. However, susceptibility of a given cell line can be influenced by variations in the applied infectious dose. Especially under conditions of high cellular susceptibility, a low viral load is sufficient to initiate an efficient infectious cycle. Thus, we included a slightly higher and lower MOI in addition to the previously published MOI of 1.5 [8], namely an MOI of $0.5,1.5$, and 4.5. Figure $1 \mathrm{~A}$ shows that the number of infected cells as determined by immunofluorescence analysis with anti-capsid antibodies was increasing on both $M \Phi$ types with a higher MOI. Hereafter, the time-dependent release of extracellular virus particles was studied under these three different MOIs. Except for $12 \mathrm{~h}$ post-infection (hpi) on GM-M $\Phi$, similar amounts of virus particles were present after infection with different MOIs (Figure 1B). This could reflect a faster uptake rate or an earlier initiation of the replication cycle on $\mathrm{M}-\mathrm{M} \Phi$. An increase in extracellular infectious particles by about one log-step occurred for both $M \Phi$ types and all applied MOIs between 12 and 24 hpi (Figure 1B,C). As a next step, we addressed RuV-associated apoptosis activation in $\mathrm{M} \Phi$. Although RuV displays in only on a limited number of cell lines a cytopathic effect $[28,29], \mathrm{RuV}$ infection activates an apoptotic response [29,30]. As an early marker for apoptotic events, we performed an assay with a cleavable and non-fluorescent DEVD peptide bound to a nucleic acid intercalating dye. This dye visualizes caspase- $3 / 7$ cleavage activity through fluorescent dye-positive signals in the nucleus, which were counted by fluorescence microscopy. At 24 hpi even after a high MOI the number of apoptotic cells did not exceed $10 \%$ of the total cell number (Figure 1D). At $48 \mathrm{hpi}$ and after a high MOI of 4.5 the number of apoptotic cells in $\mathrm{M}-\mathrm{M} \Phi$ were with $18.7 \pm 4.3 \%$ slightly higher than in GM-MФ with $12.4 \pm 4.8 \%$ (Figure 1D). Based on infection rate and apoptosis induction, we applied an MOI of 1.5 in subsequent experiments. In conclusion, a variation in the initial viral load revealed only slight variations in the course of infection, especially in the kinetics of the production of extracellular virus particles and in the activation of apoptosis.

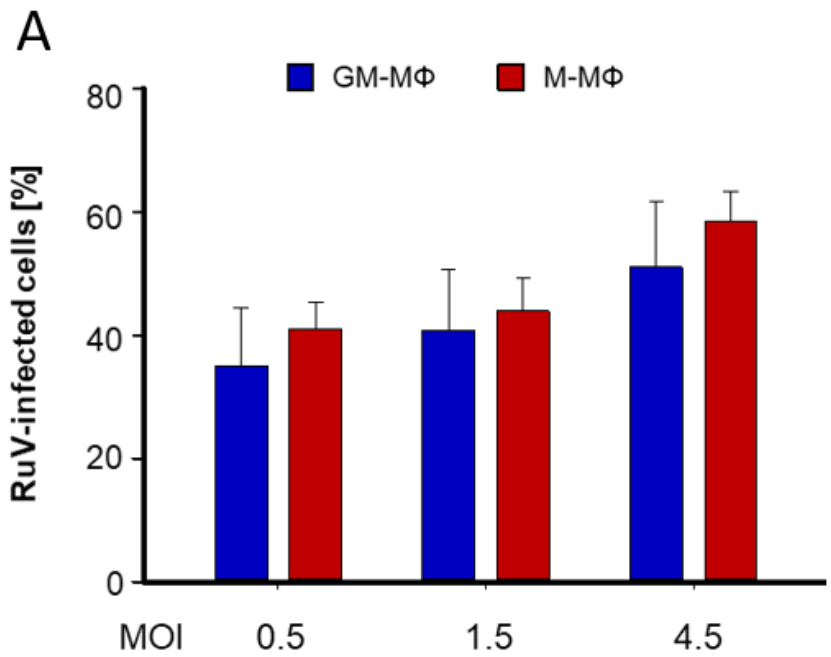

Figure 1. Cont.
B

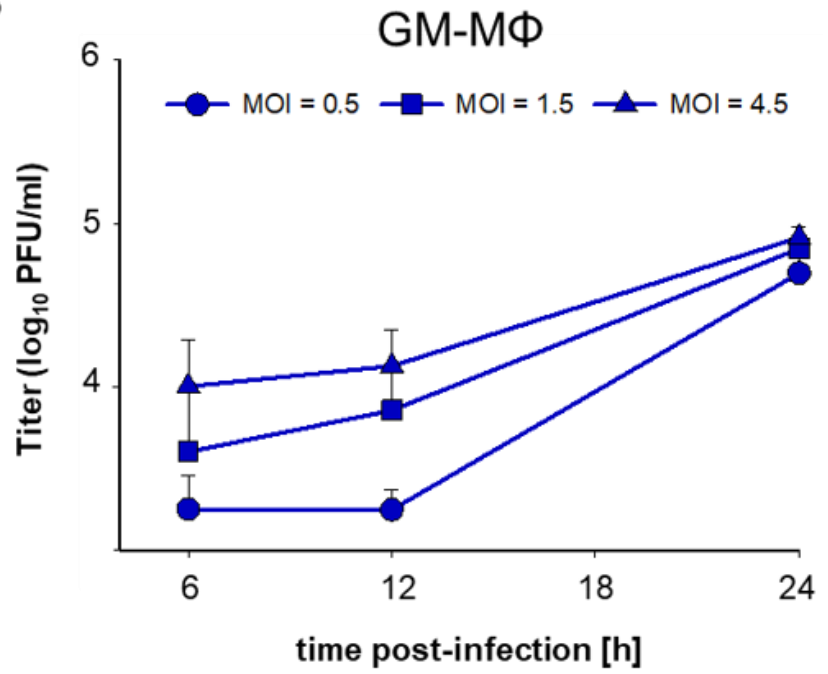



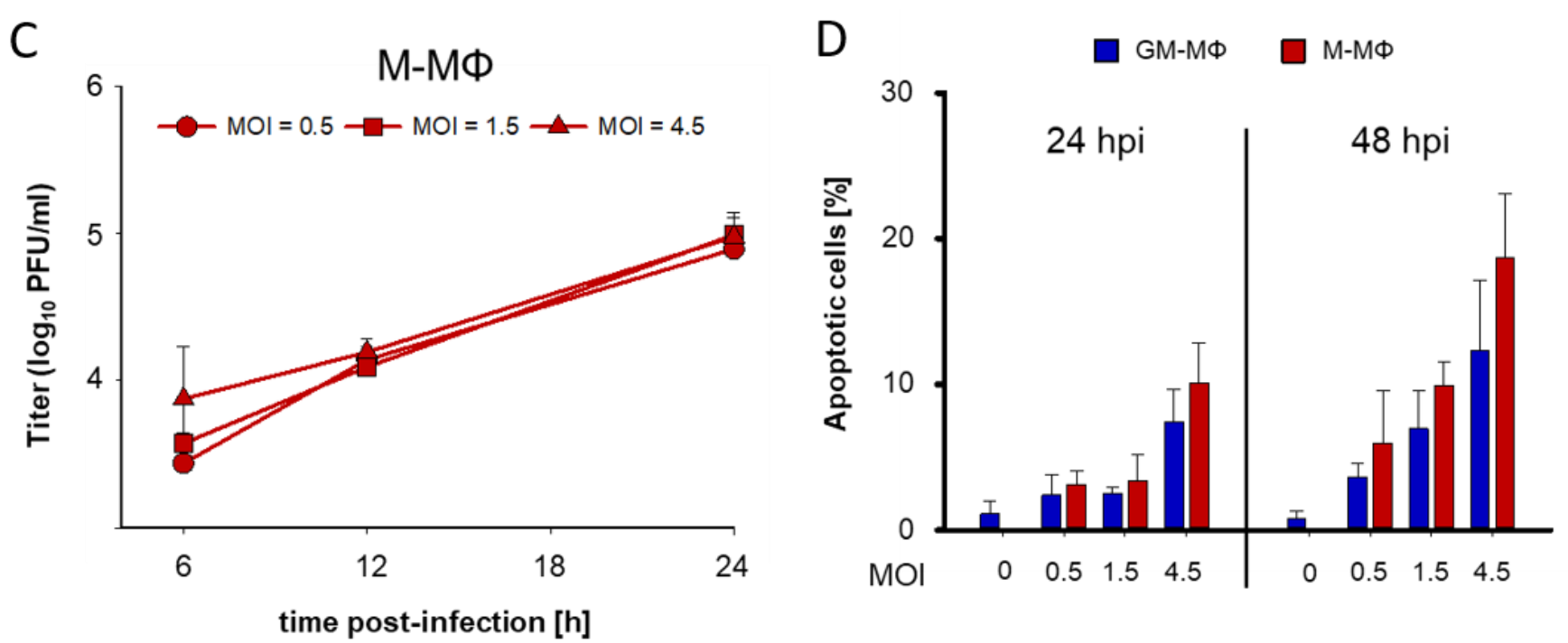

Figure 1. A higher initial infectious dose in GM- and M-MФs influences early release of extracellular virus particles and apoptosis induction. After infection of GM- and M-M $\Phi$ with three different MOIs the course of infection was analysed. (A) The number of RuV-positive cells was determined at $24 \mathrm{hpi}$ through immunofluorescence analysis with anti-capsid antibodies. (B,C) The number of extracellular virus particles was determined by standard plaque assay. (D) Apoptotic cells were counted on a fluorescent microscope as cells with CellEvent Caspase 3/7 green reagent-positive nuclei in reference to the total cell number. (A,D) Two random fields per microscope slide were counted $(n=3$, biological replicates). Total cell number was determined through a DNA intercalating dye.

\subsection{During RuV Infection of MФs the Expression of the Pattern Recognition Receptor CD14 Is Reduced}

CD14 is not only an innate immune receptor, but also a $M \Phi$ differentiation marker. Thus, we first compared its expression level on both $M \Phi$ types by flow cytometric analysis over time of their cultivation. At all analysed time points, the CD14 surface expression level was higher on GM- than on M-M $\Phi$ (Figure 2A). In agreement with previous reports [31,32], the CD14 surface expression level on both $M \Phi$ types dropped over the first $24 \mathrm{~h}$ of cultivation and remained at a comparable level between 24 and $48 \mathrm{~h}$ after plating (Figure 2A). Hereafter we addressed the CD14 expression level on both $\mathrm{M} \Phi$ types after RuV infection. The similar course of infection of RuV on GM- and M-M $\Phi$ allows for such a comparative analysis, as identified differences are unlikely to be caused by differences in the infection kinetics. As an additional control, we also addressed the impact of UV-inactivated RuV $\left(\mathrm{RuV}^{\mathrm{UV}}\right)$ on CD14 expression, as $\mathrm{M} \Phi$ are prone to sense pathogens. $\mathrm{RuV}^{\mathrm{UV}}$ allows for identification of aspects that are associated with the recognition of the virion and in the absence of a productive replication cycle. The drop in CD14 surface expression over the first $24 \mathrm{~h}$ of $M \Phi$ cultivation (Figure 2A) was also reflected by a decrease in the mRNA expression in mock-, RuV UV - and RuV-infected GM-M $\Phi$ (Figure 2B) and M-M $\Phi$ (Figure 2C). In comparison to the mock control, $\mathrm{RuV}$ infection resulted in a reduction in CD14 mRNA expression in both, GM- and M-M $\Phi$ at 24 hpi (Figure 2B,C). Additionally, both $\mathrm{M} \Phi$ types responded to $\mathrm{RuV}^{\mathrm{UV}}$ through an increase in CD14 mRNA. On M-M $\Phi$ these changes induced by $\mathrm{RuV}$ and $\mathrm{RuV}^{\mathrm{UV}}$ were significant in comparison to the mock-infected control. Accordingly, the $\mathrm{RuV}$ infection-associated impact on CD14 was also reflected by a significant reduction in CD14 in the total cell lysate from M-M $\Phi$ extracted at 24 hpi (Figure 2D). Endocytosed CD14 is degraded in lysosomes [33]. Thus, we hypothesized, that a low abundance of CD14 mRNA as seen for RuV-infected M $\Phi$ would not be able to replenish the CD14 pool at the surface. We addressed this aspect by flow cytometric analysis at 24 and $48 \mathrm{~h}$ to take the turn-over rate of CD14 into account. In comparison to the mock control, a decrease in CD14 surface expression was detected for both $M \Phi$ types with a significant reduction for M-MФs at 48 hpi (Figure 2E). The impact of RuV on CD14 expression level is especially 
noteworthy, as $\mathrm{M} \Phi$ infected with $\mathrm{RuV}^{\mathrm{UV}}$ showed the opposite tendency of RuV: CD14 surface expression level was increased in comparison to the mock-infected cells (Figure 2D). Taken together, a productive RuV infection reduced CD14 expression. This impact was

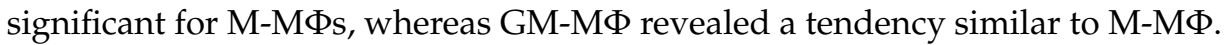
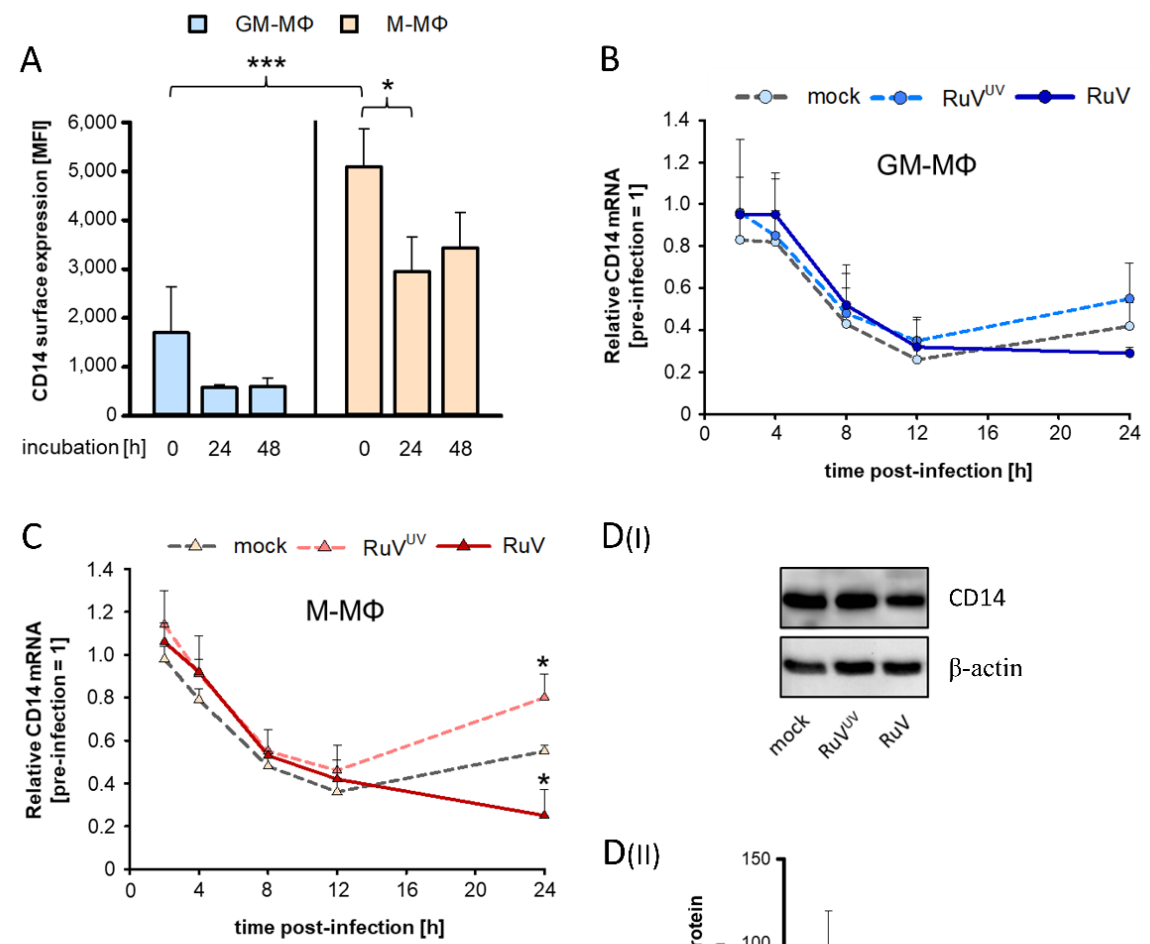

$\mathrm{D}(\mathrm{I})$
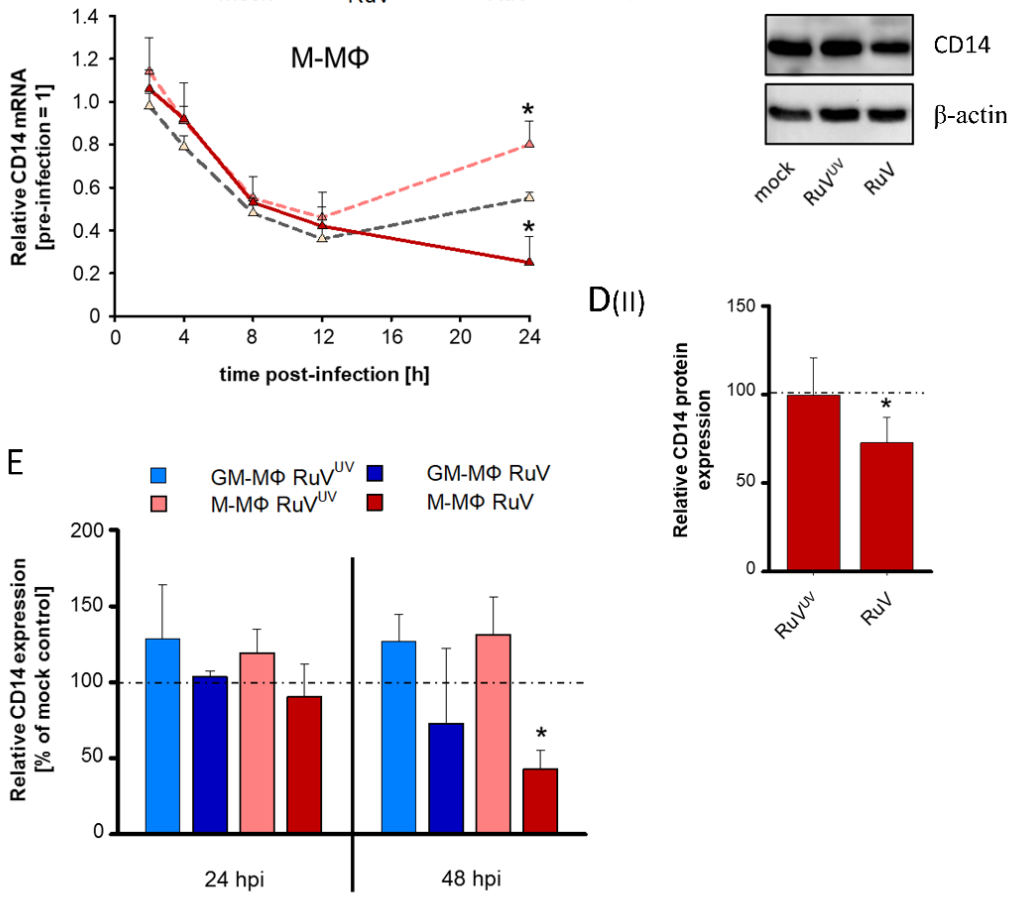

$\mathrm{D}(\mathrm{II})$

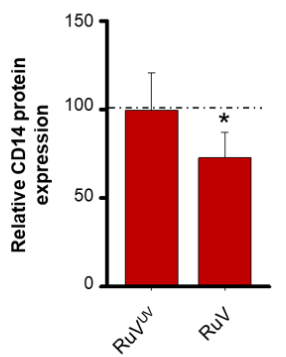

Figure 2. Downregulation of CD14 expression in GM- and M-MФs after RuV infection. (A) Surface expression of CD14 on uninfected M $\Phi$ was determined by flow cytometric analysis for indicated time points after plating of MФs. Data represent mean fluorescence intensity (MFI) \pm SD $(n=3)$. Statistical analysis was performed using ANOVA test. (B,C) At 2, 4, 8, 12, and 24 hpi CD14 mRNA level was quantified by qPCR relative to the before infection control $(0 \mathrm{hpi}=1)$. Statistical analysis was performed using Student's $t$-test and significance was calculated to the respective mock control. (DI,DII) RIPA lysates were generated from RuV- and $\mathrm{RuV}^{\mathrm{UV}}$-infected M $\Phi$ s at 24 hpi and analysed by Western blot with anti-E1 and $\beta$-actin antibodies. (DI) One representative blot out of three is shown. (DII) Western blot bands were quantified and E1 protein was normalized to loading control $\beta$-actin. Data represent means \pm SD $(n=3)$. Statistical analysis was performed using ANOVA test and significance was calculated to the mock control. (E) At 24 and 48 hpi CD14 surface expression on RuVand $\mathrm{RuV}^{\mathrm{UV}}$-infected M $\Phi$ was determined by flow cytometric analysis. Percent values of MFI \pm SD are shown $(n=3)$ and expressed as percent change compared to mock control $(=100 \%)$. Student's $t$-test was performed for statistical analysis and significance was calculated to the mock control. ${ }^{*} p \leq 0.05,{ }^{* * *} p \leq 0.001$. 


\subsection{Glycolytic Reserve of $M \Phi$ Was Lost in the Presence of IFN- $\beta$}

In response to $\mathrm{RuV}$ infection, GM- and M-M $\Phi$ generate type I and III IFNs $[8,19]$. The infection with $\mathrm{RuV}^{\mathrm{UV}}$ induced no IFN- $\beta$ production [8]. Our own published data shows that at 24 hpi IFN- $\beta$ as an antiviral response to RuV infection was generated on GM- and $\mathrm{M}-\mathrm{M} \Phi$ at a concentration of $219 \pm 170 \mathrm{pg} / \mathrm{mL}$ and $666 \pm 199 \mathrm{pg} / \mathrm{mL}$, respectively [8]. This is also illustrated in Supplementary Figure S2, which indicates the generation of IFN- at a concentration of $466 \pm 119 \mathrm{pg} / \mathrm{mL}$ on M-M $\Phi$ at $24 \mathrm{hpi}$. After medium change performed at $24 \mathrm{hpi}$ IFN- $\beta$ dropped to a concentration of $59 \pm 38 \mathrm{pg} / \mathrm{mL}$ after an additional incubation of $24 \mathrm{~h}$. In order to investigate which effects of the RuV infection on $\mathrm{M}-\mathrm{M} \Phi$ are associated with IFN- $\beta$ production, exogenous IFN- $\beta$ was applied to M-M $\Phi$ and compared to RuV infection. Subsequent IFN-associated signalling might alter the expression of surface receptors on $M \Phi$ and affect their metabolic state. Thus, we next addressed the influence of IFN- $\beta$ through its exogenous application. First, we analysed CD40, CD80 and CD86 besides CD14 on RuV-infected and exogenous IFN- $\beta$-treated $M \Phi$ at an incubation interval of 24 and 48 h. CD40, CD80, and CD86 are markers for GM-M $\Phi$ and important for activation of the adaptive immunity. Furthermore, they can be activated by TLR signalling: upon TLR3-stimulation these markers were upregulated on murine and human M2 M $\Phi$ in an IFN- $\alpha / \beta$-dependent manner, which rendered their phenotype more M1-like [34]. The analysis of their surface expression revealed similar and differential effects between $\mathrm{RuV}$ infection and exogenous IFN- $\beta$ : CD40 and CD86 were induced under both conditions, whereas the downregulation of CD14 and the upregulation of CD80 were specific for $\mathrm{RuV}$ infection (Figure 3A). Thus, in the presence of RuV the expression of the GM-M $\Phi$ markers CD40, CD80, and CD86 were increased indicative for a shift in polarization characteristics. Under these conditions, the influence of $\mathrm{RuV}^{\mathrm{UV}}$ infection on the surface expression of the examined markers was not significant in comparison to the mock control (Figure 3A). Second, the metabolic impact of RuV infection and exogenous IFN- $\beta$-treatment was examined. We focused on $\mathrm{M}-\mathrm{M} \Phi$, as alterations in CD14 were more pronounced than in GM-M $\Phi$ (Figure 3A). For metabolic analysis extracellular flux analysis with the glycolysis stress test kit was used, as the activation of $M \Phi$ is known to be associated with an increase in glycolysis [35,36]. Supplementary Figure S1 reflects the terms glycolysis, glycolytic capacity and glycolytic reserve based on the successive injection of glucose, the ATPase inhibitor oligomycin and the glycolysis inhibitor 2-deoxy-glucose. Figure 3B(I) underlines that although after $\mathrm{RuV}$ infection glycolysis and glycolytic capacity did not shift significantly compared to the mock control; the glycolytic reserve changed significantly and was no longer measurable. Comparable to RuV infection of $\mathrm{M}-\mathrm{M} \Phi$, co-incubation of mock- and $\mathrm{RuV}^{\mathrm{UV}}$-controls with exogenous IFN- $\beta(10 \mathrm{ng} / \mathrm{mL})$ did also reduce glycolytic capacity and abolish glycolytic reserve (Figure 3B(II)). In summary, our data suggests that while the impact of RuV infection on CD14 surface expression appears to be independent from IFN- $\beta$ response, the RuV-induced alteration of glycolytic activity in M-M $\Phi$ was highly similar to metabolic inhibition by IFN- $\beta$. 


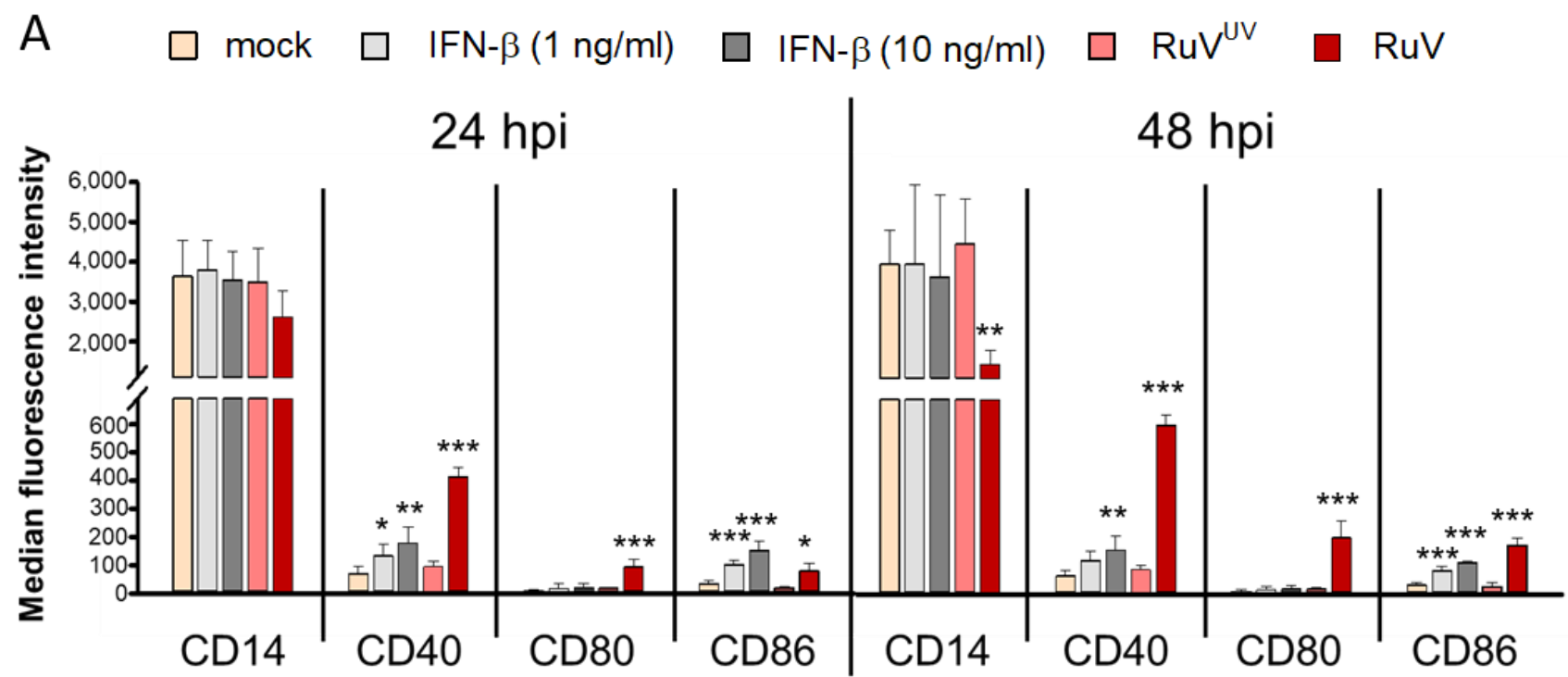

\section{Glycolysis $\square$ Glycolytic capacity $\square$ Glycolytic reserve}

$\mathrm{B}(\mathrm{I})$

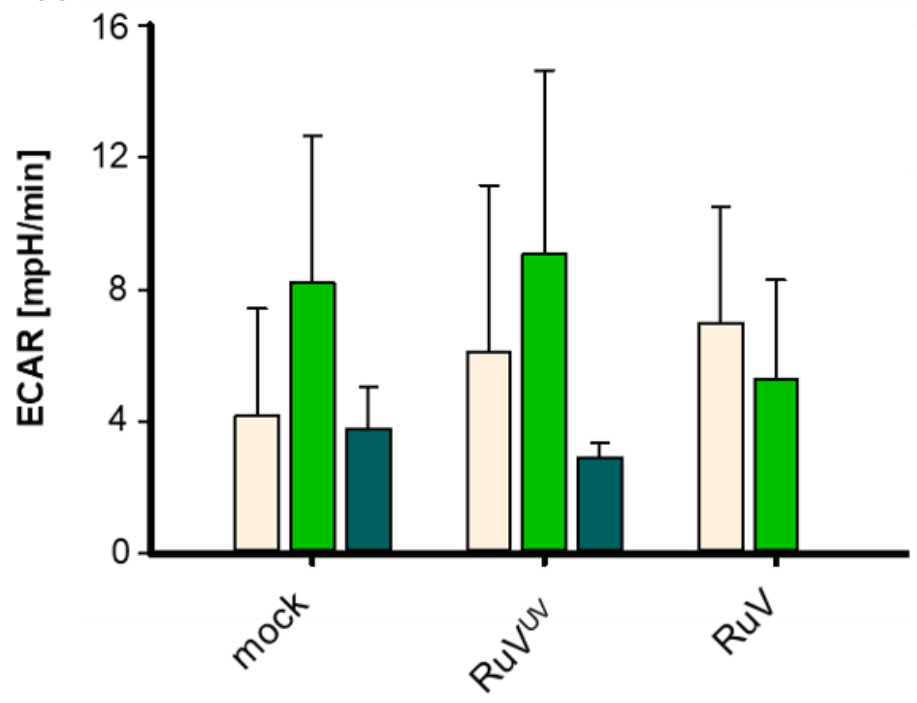

$\mathrm{B}(\mathrm{II})$

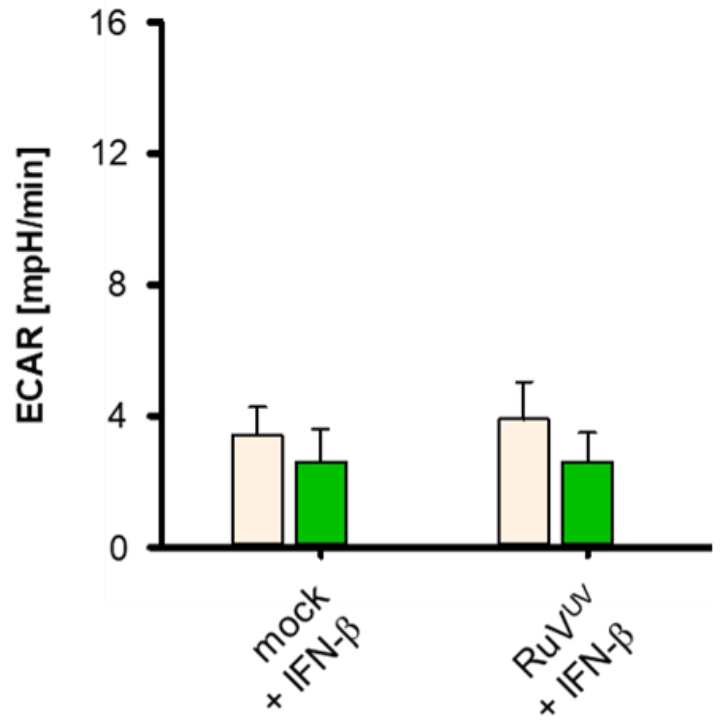

Figure 3. During RuV infection and in the presence of exogenous IFN- $\beta$ glycolytic reserve was lost in M-MФ. (A) Analysis of surface expression of CD14, CD40, CD80, and CD86 in mock-, RuV ${ }^{\mathrm{UV}}$-, and RuV-infected and exogenous IFN- $\beta$ treated GM- and M-M $\Phi$ by flow cytometry after indicated incubation intervals. Relative surface marker expression after application of exogenous IFN- $\beta$ $(10 \mathrm{ng} / \mathrm{mL})$ for $24 \mathrm{~h}$ was assessed by flow cytometry with the respective antibodies. Values $(n=3)$ of the isotype-corrected MFI \pm SD are shown. Statistical analysis was performed using ANOVA test and significance was calculated to the respective mock control. (B) M-M $\Phi\left(5 \times 10^{5} / \mathrm{mL}\right)$ were (BI) mockinfected or infected with $\mathrm{RuV}^{\mathrm{UV}}$ or RuV or (BII) mock- and $\mathrm{RuV}^{\mathrm{UV}}$-infected in the presence of IFN- $\beta$ $(10 \mathrm{ng} / \mathrm{mL})$. Glycolysis was measured through extracellular flux analysis as real-time ECAR by the glycolysis stress test and successive injection of glucose to measure glycolysis and of oligomycin to measure glycolytic capacity and reserve. Data are shown in bars as the mean plus standard deviation $( \pm S D)$ and were derived from three independent experiments with two wells per sample and experiment. ${ }^{*} p \leq 0.05,{ }^{* *} p \leq 0.01,{ }^{* * *} p \leq 0.001$. 


\subsection{Blockage of CD14 Prior to RuV Infection of M-MФs Reduces the Associated IFN Response}

CD14 is a surface receptor and serves as a marker during differentiation of monocytes into MФs [37]. Antibody-mediated blockage of CD14 is a feasible approach to study its function. Blockage results directly in loss of CD14 receptor functions, such that expression of CD14 can be maintained during in vitro differentiation of monocytes [21]. Thus, we addressed the role of CD14 during RuV infection through the application of blocking antibodies to M-MФs, as CD14 was significantly reduced on this M $\Phi$ subtype after $\mathrm{RuV}$ infection (Figure 2). As expected, Western blot analysis reflects a significant reduction in CD14 through blocking antibodies in comparison to the isotype control (Figure 4(AI,AII)). Moreover, under either condition, blocking antibodies or isotype control, the expression of CD14 in RuV-infected M-MФs was lower than in the mock controls (Figure 4AI). According to the application scheme shown in Figure 4, anti-CD14 antibodies were applied prior to infection with $\mathrm{RuV}$. Thereafter the generation of extracellular virus particles as an indicator for virus replication and particle production efficiency was determined. In agreement with a slightly increased amount of viral E1 protein after application of anti-CD14 blocking antibodies, extracellular virus particles were increased compared to the isotype control (Figure 4B). As a next step we addressed, whether blockage of CD14 alters glycolytic activity as it was noted after RuV infection and after application of exogenous IFN- $\beta$ (Figure 3B). Figure $4 \mathrm{C}$ reveals a similar glycolytic activity between blocking antibodies and isotype control. Thus, blockage of CD14 did not alter metabolic activity. As metabolic activity appeared not to be influenced, we addressed the inflammatory response through analysis of the chemokine/cytokine response. Notably, the application of anti-CD14 blocking antibodies significantly reduced the mRNA expression level of IFN- $\beta$ and IFN- $\lambda 1$ and TNF$\alpha$, whereas the chemokine CXCL10 (IP-10) was not affected (Figure 4D). This reduction was also present at the protein level: compared to the isotype control, a multiplex beadbased assay revealed a significant reduction of IFN- $\beta$ and IFN- $\lambda 1$ in the supernatant of $\mathrm{RuV}$-infected M-M $\Phi$ with application of anti-CD14 antibodies (Figure 4E) and tendency of reduction for TNF- $\alpha$, whereas CXCL10 was not altered (Figure 4F). Collectively our data point toward a CD14-dependent expression of IFNs during $\mathrm{RuV}$ infection of $\mathrm{M} \Phi$ and a rather pro-viral involvement of the $\mathrm{RuV}$ infection-associated decrease in CD14 expression.
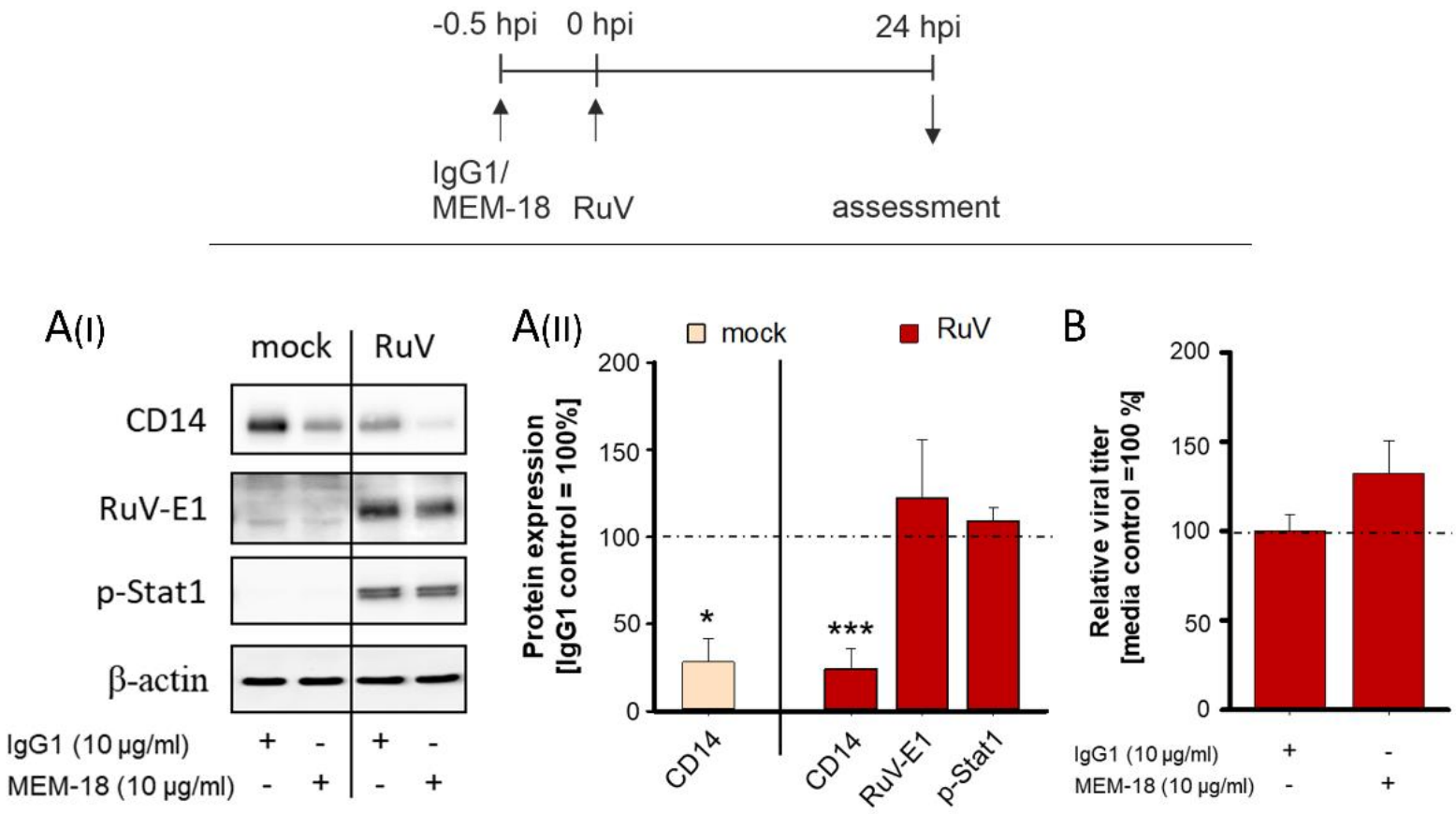

Figure 4. Cont. 
C

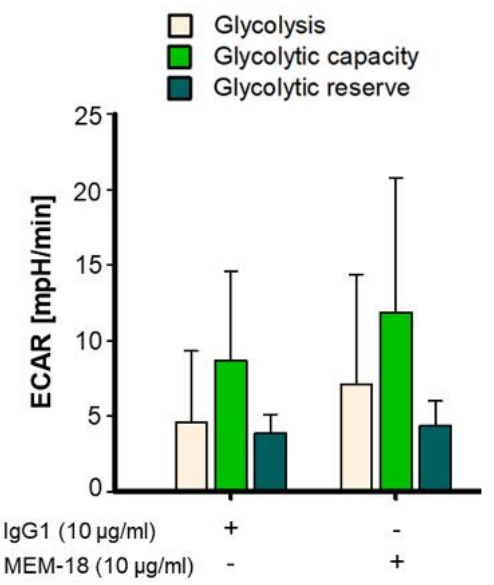

E

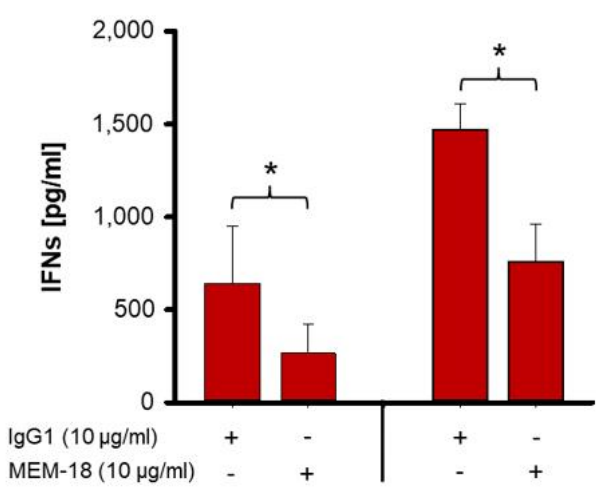

IFN- $\beta$

IFN- $\lambda 1$
D

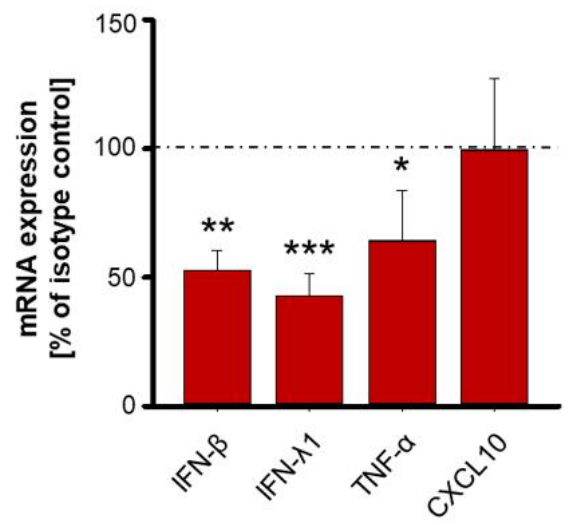

F

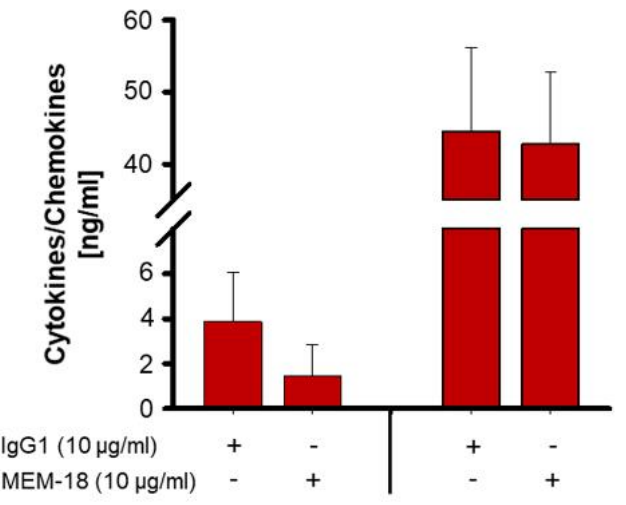

TNF- $\alpha$

CXCL10

Figure 4. The application of blocking antibodies prior to RuV infection of M-M $\Phi$ reveals CD14dependent and -independent mechanisms of the associated inflammatory response. Anti-CD14 blocking or corresponding isotype control antibodies were applied to M-M $\Phi\left(5 \times 10^{5} / \mathrm{mL}\right) 30$ min before control infection or infection with RuV. (A) Western blot analysis of protein lysates (30 $\mu \mathrm{g} / \mathrm{lane})$ with anti-CD14, anti-E1 and anti- $\beta$-actin antibodies at 24 hpi. (AI) One representative Western blot from independent experiments of four donors is shown. (AII) Western blot results were subjected to densitometric analysis for quantification of expression changes $(n=4)$. Statistical analysis was performed using ANOVA test and significance was calculated to the respective isotype control (B) Extracellular virus particles were determined at 24 hpi by plaque assay. Percent values of the means $\pm \mathrm{SD}$ are shown $(n=3)$ and expressed as percent change compared to isotype control. (C) M-MФs were subjected to extracellular flux analysis with the glycolysis stress test $24 \mathrm{~h}$ after addition of the blocking and control antibodies. Glycolysis and glycolytic capacity/reserve were measured through successive injection of glucose and oligomycin, respectively. Data are shown in bars as the mean plus standard deviation $( \pm S D)$ and were derived from three independent experiments with two wells per sample and experiment. (D) The mRNA expression of the indicated cytokines/chemokines in RuV-infected MФs was determined at 24 hpi by quantitative real-time PCR. Data normalization was carried out with GNB2L1. Relative mRNA quantification based on $2^{-\Delta \Delta C t}$ was employed. Expression of indicated target mRNA was determined relative to isotype control (isotype control $=100 \%) \pm \mathrm{SD}(n=3$ ). Statistical analysis was performed using ANOVA test and significance was calculated to the isotype control. (E,F) The protein concentrations of the indicated cytokines/chemokines in supernatants of $\mathrm{RuV}$-infected MФs were determined at 24 hpi by LEGENDPLEX human interferon panel kit (IFN- $\beta$, IFN- $\lambda 1$ and TNF- $\alpha$ ) or ELISA (CXCL10). Data are shown in bars as the mean plus standard deviation $( \pm \mathrm{SD})(n=3)$. Statistical analysis was performed using ANOVA test and significance was calculated to the respective isotype control. ${ }^{*} p \leq 0.05,{ }^{* *} p \leq 0.01,{ }^{* * *} p \leq 0.001$. 
The main conclusions of our manuscript are summarized in Figure 5.

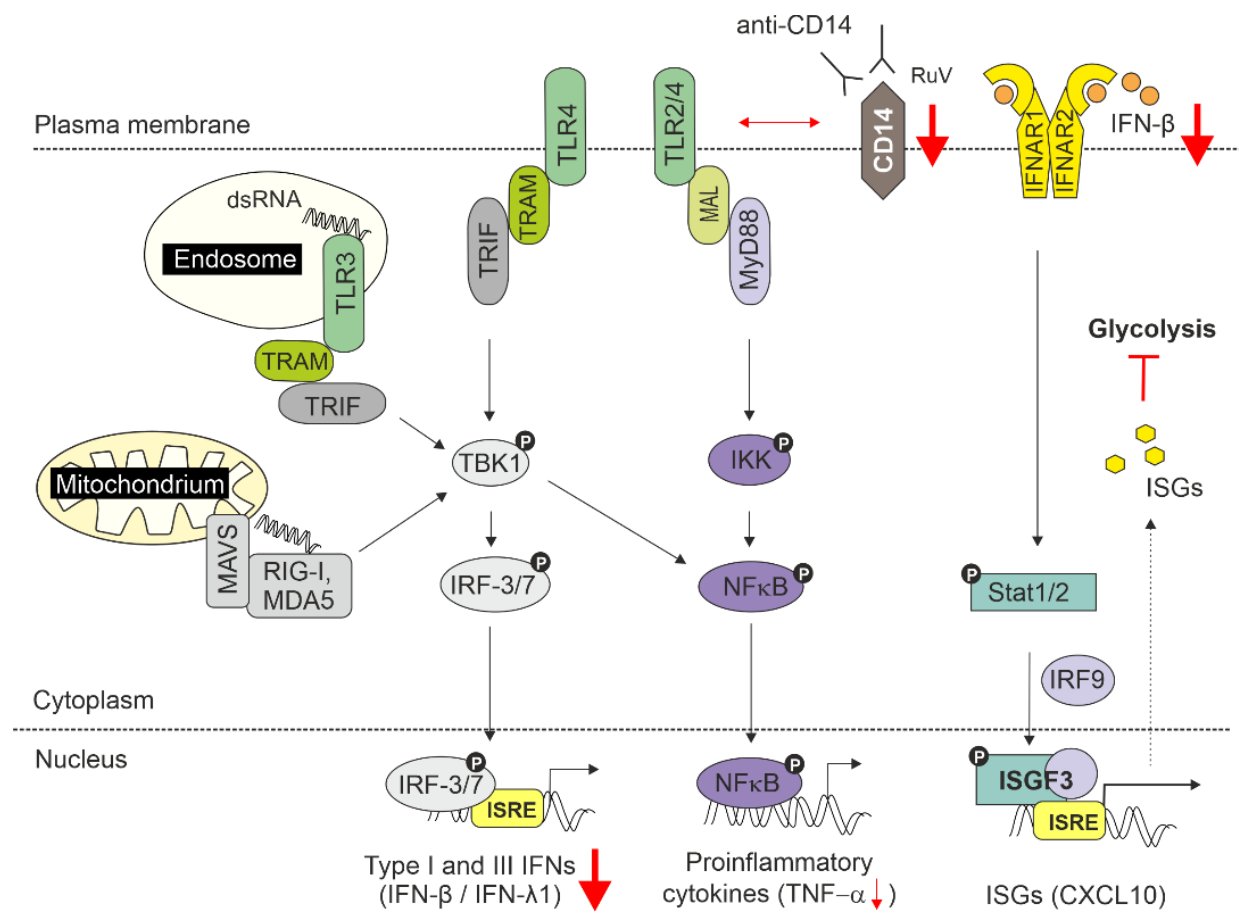

Figure 5. Summarizing figure. CD14-dependent signalling contributes to the induction of IFNs during RuV infection and potentially involves a so far unidentified TLR. As recently outlined in a review, among the TLRs involved in recognition of viral PAMPs are TLR2 and TLR4 (envelope glycoproteins) and TLR3 (dsRNA) [38]. For simplification, internalization and localization of TLR2 and TLR4 to endosomes are not depicted. All TLRs use the adaptor MyD88 except for TLR3, which signals only through TRIF. TLR3 and TLR4 interact with the adaptor TRIF. As the PRR for RuV is still unknown, RIG-I and MDA5 are included as additional PRRs for dsRNA within the cytoplasm. The associated transcriptional pathways, NFkB and IRF3/7, are illustrated. Through its association with TLRs, CD14 modulates the activation of downstream signalling pathways. The noted reduction in IFNs after application of blocking antibodies prior to $\mathrm{RuV}$ infection points towards the involvement of TRIF-dependent pathways during RuV infection. Downmodulated targets are highlighted with red arrows. The inhibitor symbol indicates the here identified inhibition of glycolysis by IFN- $\beta$.

\section{Discussion}

Virus infection-associated changes of $М \Phi$ functions contribute to downmodulation of immune functions during virus infections [39]. Thus, the investigation of these changes could support our understanding of viral pathogenesis. The persistence of reactivated $\mathrm{RuV}$ vaccine-derived viruses in M2 M $\Phi$ in patients with PID [40] suggests a contributory role of this innate immune cell type to rubella pathogenesis, which might even represent a possible cellular reservoir for $\mathrm{RuV}$. The clinical finding on maintenance of vaccine-derived $\mathrm{RuV}$ in M2 M $\Phi$ is in line with our observations in this study on the reduced expression of CD14 during RuV infection, which was more pronounced in M (M2-like)- than in GM (M1-like)-MФs. This appears to be part of virus infection-induced alterations to support virus replication as shown here through a reduced IFN response and an increase in number of extracellular virus particles after antibody-mediated blockage of CD14.

CD14 itself is a PRR and serves as a co-receptor for several TLRs, including TLR4 at the plasma membrane as well as TLR3 at the plasma membrane and in the endosome and as such CD14 fulfils multiple functions [41]. While TLR3 serves as a PRR for nucleic acids [42], TLR4 is involved in the recognition of bacterial components such as LPS, but also of viral glycoproteins as shown for Ebola virus glycoprotein [43] and the F-protein of respiratory syncytial virus [17]. The RuV PAMPs and the receptors involved in their 
recognition are still not known. Nevertheless, human nucleotide polymorphisms (SNPs) that are associated with variations in the immune response to rubella vaccination provide some indications. The cytokine response to $\mathrm{RuV}$ vaccine strain including the generation of IFN- $\gamma$, TNF- $\alpha$, and GM-CSF were affected by SNPs in the IFN- $\alpha / \beta$ receptor (IFNAR2) and the TLR3 and TLR4 genes [44-46]. Thus, the identified SNPs could be involved in a differential immune response to rubella vaccination in humans. Namely, two SNPs within the TLR3 gene were accompanied by a reduced secretion of GM-CSF [46]. In addition to the contributory role of the PRRs TLR3 and TLR4, these studies also highlight the importance of innate immune responses for the overall antiviral countermeasures against $\mathrm{RuV}$. The generation of dsRNA during $\mathrm{RuV}$ infection appears to be the main activating signal for an IFN response as $\mathrm{RuV}^{\mathrm{UV}}$ does hardly induce IFNs [8]. The relevance of the expression of the PRR CD14 on MФs for inflammatory processes is also reflected by physiological processes: absence of CD14 on resident intestinal MФs adds to the low level of inflammation within the intestinal mucosa in the presence of gut commensal microbiota [47]. The differential impact of $\mathrm{RuV}$ and $\mathrm{RuV}^{\mathrm{UV}}$ on CD14 expression and the rather low level of IFN induction after application of $\mathrm{RuV}^{\mathrm{UV}}$ [8] might be due to the activation signal imposed by viral RNA and dsRNA as replicative intermediates of the $\mathrm{RuV}$ productive replication cycle, which is not present during $\mathrm{RuV}^{\mathrm{UV}}$ infection. In line with this hypothesis, the induction of type I IFNs and pro-inflammatory cytokines by cell-free Ebola virus-like particles (eVLP) was synergistically enhanced after its co-application with Poly I:C as a dsRNA analogue, which is active through the TLR3 or RIG-I pathway [48]. Moreover, dsRNA as an activator of TLR3 can be released from virus-infected cells and as such contribute to the induction of an inflammatory response [49].

The role played by CD14 in host defence mechanisms is always protective through activation of an immune response [41], whereas the level of CD14 expression in MФs during infection depends on the type of the virus and bacterium. Comparable to infection with $\mathrm{RuV}$, the expression of ORF3 of hepatitis E virus (HEV) reduced CD14 expression [50]. In the case of human monocyte-derived MФ CMV infection is associated with a maintained high expression level of CD14 as compared to the decline in mock infection over time of cultivation [51]. The maintenance of CD14 expression during HCMV infection was discussed to fuel their pro-inflammatory response and thus contribute to the pathogenesis of HCMV through induction of inflammation in infected tissues [51,52]. By implication, this supports our hypothesis on the contribution of a reduced CD14 expression level to maintenance of RuV in $\mathrm{M}-\mathrm{M} \Phi$ s on a rather low inflammatory background as shown here through a reduced IFN expression level after blockage of CD14 prior to RuV infection. The link between CD14 expression and IFN response is also supported by literature data on the infection of murine MФs with VSV. The VSV glycoprotein activates the TLR4/CD14 complex and as such the antiviral type I IFN pathway [53]. In addition to the observed reduction in CD14 after $\mathrm{RuV}$ infection, a slight shift to a more GM-M $\Phi$ phenotype as indicated through the increase in the GM-M $\Phi$ markers CD40, CD80, and CD86 could also be associated with a lower IFN response. The $\mathrm{RuV}$-associated IFN response on GM-M $\Phi$ is lower than on M-MФ [8].

Based on our data we hypothesize that CD14 is involved in the IFN response during $\mathrm{RuV}$ infection. An open question for future research is how viruses such as $\mathrm{RuV}$ could modulate CD14 expression and how CD14 contributes to the antiviral response of MФs against RuV. CD14 lacks an intracellular domain and as such CD14 on its own is not able to transmit intracellular signals upon binding of its respective ligand. CD14 was proposed as a transporter of various ligands through the cells and was grouped as a member of the TAXI proteins, the transporters associated with the execution of inflammation [33]. Potential cofactors of CD14 as outlined hereafter include TLR3 and TLR4. As a follow-up of the study by Okumura and colleagues on the activation of TLR4 through eVLP [54], the associated signalling cascade was analysed by Ayithan and colleagues through activation of dendritic cells (DC) with eVLP [48]. Whereas the stimulation of DCs from MyD88 ${ }^{-/}$mice had no impact on IFN- $\beta$ expression and a slight effect on TNF- $\alpha$ was noted, whereas in DCs from 
TRIF $^{-/-}$mice IFN- $\beta$ was almost absent and TNF- $\alpha$ was reduced. TLR3 recognizes dsRNA and signals through TRIF, whereas the other members of the TLR family signal through MyD88 [55,56]. Further line of evidence supports the notion on the involvement of CD14 in TLR3-signalling, including the proposed interaction of CD14 with the dsRNA analogue Poly I:C in support of the activation of TLR3 [57]. This was further addressed by Rajaiah and colleagues through the application of Poly I:C to bone marrow-derived macrophages from CD14 ${ }^{-/-}$mice. The generation of TNF- $\alpha$ was greatly reduced, whereas IFN- $\beta$ was slightly reduced and CXCL10 was not altered, which suggests that some effects of TLR3 are CD14-independent or partially CD14-dependent [58]. With our data we support the notion on the involvement of CD14 in the generation of IFNs by human M $\Phi$ s in response to a virus infection.

Moreover, there are multiple points of interaction between cellular metabolism and antiviral innate immune response [59]. Our data suggests that the impact of RuV infection of the metabolic activity of M-MФs is mainly related to the presence of IFN- $\beta$. With our data on human MФs during a virus infection we complement recent data on the involvement of IFN- $\beta$ in the metabolic response of murine bone marrow-derived macrophages to infection with Mycobacterium tuberculosis and the so far undercharacterized role of type I IFNs to the metabolic response of MФs [35]. Comparable to our observations, IFN- $\beta$ induced a loss of glycolytic reserve in murine MФs [35]. Accordingly, the modulation of IFN- $\beta$ expression through alteration in CD14 expression levels could support RuV infection through a reduced impact of IFN- $\beta$ on glycolysis and as such an enhanced availability of metabolites and energy. Notably, in contrast to Mycobacterium tuberculosis infection of

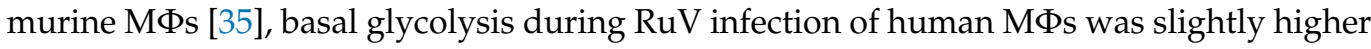
than after application of exogenous IFN- $\beta$ to control infections. Moreover, the antiviral activity of IFNs includes the induction of IFN-induced genes (ISGs), which encode antiviral proteins that interfere with various steps of the viral growth cycle. This antiviral effect by IFN- $\beta$ against $\mathrm{RuV}$ was shown in a previous study by our own group through exogenous application of IFN- $\beta$ to A549 prior RuV infection [19].

In conclusion, our study provides further evidence in support of a contributory role of CD14 to sensing of viral infections besides its known high relevance for the recognition of bacterial components. The downmodulation of CD14 appears to be supportive for RuV infection of MФs and could potentially be involved in $\mathrm{RuV}$ maintenance, as it was shown in association with M2 MФs in granulomas of PID patients [40]. The identification of high serum soluble CD14 level in COVID19 patients highlights its potential as a therapeutic target $[60,61]$. A CRISPR/Cas9 screen identified genes involved in downmodulation or upregulation of CD14 and as such pharmacological compounds that target these processes [61]. Furthermore, reactivation and persistence of RNA viruses such as RuV holds many open questions including the potential cellular reservoir. Through their access to various tissue and their involvement in tissue homeostasis MФs could be modified during virus infections to support viral persistence. Our data adds novel aspects through the involvement of CD14 in the response of human $\mathrm{M} \Phi$ s to $\mathrm{RuV}$.

Supplementary Materials: The following supporting information can be downloaded at: https: / / www.mdpi.com/article/10.3390/biomedicines10020266/s1, Figure S1: Representative illustration of the measurement conditions during glycolysis stress test. Figure S2: RuV-induced IFN- $\beta$ expression in $\mathrm{M}-\mathrm{M} \Phi$.

Author Contributions: Conceptualization, E.S., C.C. and S.H.; methodology, E.S., C.C.; validation, E.S., C.C. and S.H.; formal analysis, E.S., L.P. and C.C.; investigation, E.S., L.P. and C.C.; resources, U.K.; data curation, E.S.; writing — original draft preparation, C.C.; writing-review and editing, all authors; visualization, E.S., C.C.; supervision, S.H. and C.C. All authors have read and agreed to the published version of the manuscript.

Funding: The authors appreciate support from the German Research Foundation (DFG) and Leipzig University within the program of Open Access Publishing. 
Institutional Review Board Statement: Data collection for this study involving human participants was approved by the ethics committee of the Medical Faculty, Leipzig University, Liebigstraße 18, 04103 Leipzig under the licence 001/19-ek.

Informed Consent Statement: Informed consent was obtained from all subjects involved in the study.

Data Availability Statement: The raw data supporting the conclusions of this article will be made available by the authors, without undue reservation.

Conflicts of Interest: The authors declare no conflict of interest.

\section{References}

1. Murray, P.J.; Wynn, T.A. Protective and pathogenic functions of macrophage subsets. Nat. Rev. Immunol. 2011, $11,723-737$. [CrossRef] [PubMed]

2. Sica, A.; Mantovani, A. Macrophage plasticity and polarization: In vivo veritas. J. Clin. Investig. 2012, 122, 787-795. [CrossRef] [PubMed]

3. Viola, A.; Munari, F.; Sánchez-Rodríguez, R.; Scolaro, T.; Castegna, A. The Metabolic Signature of Macrophage Responses. Front. Immunol. 2019, 10, 1462. [CrossRef] [PubMed]

4. Muraille, E.; Leo, O.; Moser, M. TH1/TH2 paradigm extended: Macrophage polarization as an unappreciated pathogen-driven escape mechanism? Front. Immunol. 2014, 5, 603. [CrossRef] [PubMed]

5. Perelygina, L.; Icenogle, J.; Sullivan, K.E. Rubella virus-associated chronic inflammation in primary immunodeficiency diseases Curr. Opin. Allergy Clin. Immunol. 2020, 20, 574-581. [CrossRef] [PubMed]

6. van der Logt, J.T.; van Loon, A.M.; van der Veen, J. Replication of rubella virus in human mononuclear blood cells. Infect. Immun. 1980, 27, 309-314. [CrossRef] [PubMed]

7. Lazar, M.; Perelygina, L.; Martines, R.; Greer, P.; Paddock, C.D.; Peltecu, G.; Lupulescu, E.; Icenogle, J.; Zaki, S.R. Immunolocalization and Distribution of Rubella Antigen in Fatal Congenital Rubella Syndrome. EBioMedicine 2016, 3, 86-92. [CrossRef]

8. Schilling, E.; Grahnert, A.; Pfeiffer, L.; Koehl, U.; Claus, C.; Hauschildt, S. The Impact of Rubella Virus Infection on a Secondary Inflammatory Response in Polarized Human Macrophages. Front. Immunol. 2021, 12, 5292. [CrossRef]

9. Bennett, A.J.; Paskey, A.C.; Ebinger, A.; Pfaff, F.; Priemer, G.; Höper, D.; Breithaupt, A.; Heuser, E.; Ulrich, R.G.; Kuhn, J.H.; et al. Relatives of rubella virus in diverse mammals. Nature 2020, 586, 424-428. [CrossRef]

10. Perelygina, L.; Chen, M.-H.; Suppiah, S.; Adebayo, A.; Abernathy, E.; Dorsey, M.; Bercovitch, L.; Paris, K.; White, K.P.; Krol, A.; et al. Infectious vaccine-derived rubella viruses emerge, persist, and evolve in cutaneous granulomas of children with primary immunodeficiencies. PLoS Pathog. 2019, 15, e1008080. [CrossRef]

11. Plotkin, S.A. The history of rubella and rubella vaccination leading to elimination. Clin. Infect. Dis. 2006, 43, S164-S168. [CrossRef] [PubMed]

12. Wu, Z.; Zhang, Z.; Lei, Z.; Lei, P. CD14: Biology and role in the pathogenesis of disease. Cytokine Growth Factor Rev. 2019, 48, 24-31. [CrossRef] [PubMed]

13. Ostuni, R.; Zanoni, I.; Granucci, F. Deciphering the complexity of Toll-like receptor signaling. Cell. Mol. Life Sci. 2010, 67, 4109-4134. [CrossRef] [PubMed]

14. Asea, A.; Rehli, M.; Kabingu, E.; Boch, J.A.; Bare, O.; Auron, P.E.; Stevenson, M.A.; Calderwood, S.K. Novel signal transduction pathway utilized by extracellular HSP70: Role of toll-like receptor (TLR) 2 and TLR4. J. Biol. Chem. 2002, 277, 15028-15034. [CrossRef]

15. Pugin, J.; Heumann, D.; Tomasz, A.; Kravchenko, V.V.; Akamatsu, Y.; Nishijima, M.; Glauser, M.P.; Tobias, P.S.; Ulevitch, R.J. CD14 Is a pattern recognition receptor. Immunity 1994, 1, 509-516. [CrossRef]

16. Wright, S.D.; Ramos, R.A.; Tobias, P.S.; Ulevitch, R.J.; Mathison, J.C. CD14, a receptor for complexes of lipopolysaccharide (LPS) and LPS binding protein. Science 1990, 249, 1431-1433. [CrossRef]

17. Kurt-Jones, E.A.; Popova, L.; Kwinn, L.; Haynes, L.M.; Jones, L.P.; Tripp, R.A.; Walsh, E.E.; Freeman, M.W.; Golenbock, D.T.; Anderson, L.J.; et al. Pattern recognition receptors TLR4 and CD14 mediate response to respiratory syncytial virus. Nat. Immunol. 2000, 1, 398-401. [CrossRef]

18. Compton, T.; Kurt-Jones, E.A.; Boehme, K.W.; Belko, J.; Latz, E.; Golenbock, D.T.; Finberg, R.W. Human cytomegalovirus activates inflammatory cytokine responses via CD14 and Toll-like receptor 2. J. Virol. 2003, 77, 4588-4596. [CrossRef]

19. Zobel, S.; Lorenz, M.; Frascaroli, G.; Böhnke, J.; Bilz, N.C.; Stanifer, M.L.; Boulant, S.; Bergs, S.; Liebert, U.G.; Claus, C. Rubella Virus Strain-Associated Differences in the Induction of Oxidative Stress Are Independent of Their Interferon Activation. Viruses 2018, 10, 540. [CrossRef]

20. Schilling, E.; Weiss, R.; Grahnert, A.; Bitar, M.; Sack, U.; Hauschildt, S. Molecular mechanism of LPS-induced TNF- $\alpha$ biosyn-thesis in polarized human macrophages. Mol. Immunol. 2018, 93, 206-215. [CrossRef]

21. Grahnert, A.; Weiss, R.; Schilling, E.; Stanslowsky, N.; Sack, U.; Hauschildt, S. CD14 Counterregulates Lipopolysacha-ride-Induced Tumor Necrosis Factor- $\alpha$ Production in a Macrophage Subset. J. Innate Immun. 2019, 11, 359-374. [CrossRef] [PubMed]

22. Ishii, T.; Wallace, A.M.; Zhang, X.; Gosselink, J.; Abboud, R.T.; English, J.C.; Paré, P.D.; Sandford, A.J. Stability of housekeeping genes in alveolar macrophages from COPD patients. Eur. Respir. J. 2006, 27, 300-306. [CrossRef] [PubMed] 
23. Li, P.; Wong, J.J.-Y.; Sum, C.; Sin, W.-X.; Ng, K.-Q.; Koh, M.B.C.; Chin, K.-C. IRF8 and IRF3 cooperatively regulate rapid interferon- $\beta$ induction in human blood monocytes. Blood 2011, 117, 2847-2854. [CrossRef] [PubMed]

24. Bender, S.; Reuter, A.; Eberle, F.; Einhorn, E.; Binder, M.; Bartenschlager, R. Activation of Type I and III Interferon Response by Mitochondrial and Peroxisomal MAVS and Inhibition by Hepatitis C Virus. PLoS Pathog. 2015, 11, e1005264. [CrossRef] [PubMed]

25. Schilling, E.; Wehrhahn, J.; Klein, C.; Raulien, N.; Ceglarek, U.; Hauschildt, S. Inhibition of nicotinamide phosphoribosyltransferase modifies LPS-induced inflammatory responses of human monocytes. Innate Immun. 2012, 18, 518-530. [CrossRef] [PubMed]

26. Lu, Q.; Darveau, R.P.; Samaranayake, L.P.; Wang, C.-Y.; Jin, L. Differential modulation of human \{beta\}-defensins expression in human gingival epithelia by Porphyromonas gingivalis lipopolysaccharide with tetra- and penta-acylated lipid A structures. Innate Immun. 2009, 15, 325-335. [CrossRef]

27. Yano, S.; Banno, T.; Walsh, R.; Blumenberg, M. Transcriptional responses of human epidermal keratinocytes to cytokine interleukin-1. J. Cell. Physiol. 2008, 214, 1-13. [CrossRef]

28. McCarthy, K. Cell cultures useful for the study of rubella. Am. J. Dis. Child. 1969, 118, 78-82. [CrossRef]

29. Megyeri, K.; Berencsi, K.; Halazonetis, T.D.; Prendergast, G.C.; Gri, G.; Plotkin, S.A.; Rovera, G.; Gönczöl, E. Involvement of a p53-dependent pathway in rubella virus-induced apoptosis. Virology 1999, 259, 74-84. [CrossRef]

30. Hofmann, J.; Pletz, M.W.; Liebert, U.G. Rubella virus-induced cytopathic effect in vitro is caused by apoptosis. J. Gen. Virol. 1999, 80 Pt 7, 1657-1664. [CrossRef]

31. Bosshart, H.; Heinzelmann, M. Spontaneous decrease of CD14 cell surface expression in human peripheral blood monocytes ex vivo. J. Immunol. Methods 2011, 368, 80-83. [CrossRef] [PubMed]

32. Bazil, V.; Strominger, J.L. Shedding as a mechanism of down-modulation of CD14 on stimulated human monocytes. J. Immunol. 1991, 147, 1567-1574. [PubMed]

33. Tan, Y.; Zanoni, I.; Cullen, T.W.; Goodman, A.L.; Kagan, J.C. Mechanisms of Toll-like Receptor 4 Endocytosis Reveal a Common Immune-Evasion Strategy Used by Pathogenic and Commensal Bacteria. Immunity 2015, 43, 909-922. [CrossRef] [PubMed]

34. Vidyarthi, A.; Khan, N.; Agnihotri, T.; Negi, S.; Das, D.K.; Aqdas, M.; Chatterjee, D.; Colegio, O.R.; Tewari, M.K.; Agrewala, J.N TLR-3 Stimulation Skews M2 Macrophages to M1 Through IFN- $\alpha \beta$ Signaling and Restricts Tumor Progression. Front. Immunol. 2018, 9, 1650. [CrossRef]

35. Olson, G.S.; Murray, T.A.; Jahn, A.N.; Mai, D.; Diercks, A.H.; Gold, E.S.; Aderem, A. Type I interferon decreases macrophage energy metabolism during mycobacterial infection. Cell Rep. 2021, 35, 109195. [CrossRef]

36. Schuster, S.; Ewald, J.; Kaleta, C. Modeling the energy metabolism in immune cells. Curr. Opin. Biotechnol. 2021, 68, 282-291. [CrossRef]

37. Ziegler-Heitbrock, H.; Ulevitch, R.J. CD14: Cell surface receptor and differentiation marker. Immunol. Today 1993, 14, 121-125. [CrossRef]

38. Sartorius, R.; Trovato, M.; Manco, R.; D’Apice, L.; de Berardinis, P. Exploiting viral sensing mediated by Toll-like receptors to design innovative vaccines. NPJ Vaccines 2021, 6, 127. [CrossRef]

39. Rouse, B.T.; Horohov, D.W. Immunosuppression in viral infections. Rev. Infect. Dis. 1986, 8, 850-873. [CrossRef]

40. Perelygina, L.; Plotkin, S.; Russo, P.; Hautala, T.; Bonilla, F.; Ochs, H.D.; Joshi, A.; Routes, J.; Patel, K.; Wehr, C.; et al. Rubella persistence in epidermal keratinocytes and granuloma M2 macrophages in patients with primary immunodeficiencies. J. Allergy Clin. Immunol. 2016, 138, 1436-1439.e11. [CrossRef]

41. Zanoni, I.; Granucci, F. Role of CD14 in host protection against infections and in metabolism regulation. Front. Cell. Infect. Microbiol. 2013, 3, 32. [CrossRef] [PubMed]

42. Alexopoulou, L.; Holt, A.C.; Medzhitov, R.; Flavell, R.A. Recognition of double-stranded RNA and activation of NF-kappaB by Toll-like receptor 3. Nature 2001, 413, 732-738. [CrossRef] [PubMed]

43. Lai, C.-Y.; Strange, D.P.; Wong, T.A.S.; Lehrer, A.T.; Verma, S. Ebola Virus Glycoprotein Induces an Innate Immune Response In vivo via TLR4. Front. Microbiol. 2017, 8, 1571. [CrossRef] [PubMed]

44. Ovsyannikova, I.G.; Salk, H.M.; Larrabee, B.R.; Pankratz, V.S.; Poland, G.A. Single-nucleotide polymorphism associations in common with immune responses to measles and rubella vaccines. Immunogenetics 2014, 66, 663-669. [CrossRef] [PubMed]

45. Ovsyannikova, I.G.; Salk, H.M.; Larrabee, B.R.; Pankratz, V.S.; Poland, G.A. Single nucleotide polymorphisms/haplotypes associated with multiple rubella-specific immune response outcomes post-MMR immunization in healthy children. Immunogenetics 2015, 67, 547-561. [CrossRef] [PubMed]

46. Ovsyannikova, I.G.; Dhiman, N.; Haralambieva, I.H.; Vierkant, R.A.; O’Byrne, M.M.; Jacobson, R.M.; Poland, G.A. Rubella vaccine-induced cellular immunity: Evidence of associations with polymorphisms in the Toll-like, vitamin A and D receptors, and innate immune response genes. Hum. Genet. 2010, 127, 207-221. [CrossRef]

47. Smith, P.D.; Smythies, L.E.; Mosteller-Barnum, M.; Sibley, D.A.; Russell, M.W.; Merger, M.; Sellers, M.T.; Orenstein, J.M.; Shimada, T.; Graham, M.F.; et al. Intestinal macrophages lack CD14 and CD89 and consequently are down-regulated for LPS- and IgA-mediated activities. J. Immunol. 2001, 167, 2651-2656. [CrossRef]

48. Ayithan, N.; Bradfute, S.B.; Anthony, S.M.; Stuthman, K.S.; Dye, J.M.; Bavari, S.; Bray, M.; Ozato, K. Ebola virus-like particles stimulate type I interferons and proinflammatory cytokine expression through the toll-like receptor and interferon signaling pathways. J. Interferon Cytokine Res. 2014, 34, 79-89. [CrossRef]

49. Nguyen, T.A.; Whitehead, L.; Pang, K.C. Quantification of Extracellular Double-stranded RNA Uptake and Subcellular Localization Using Flow Cytometry and Confocal Microscopy. Bio Protoc. 2018, 8, e2890. [CrossRef] 
50. Lei, Q.; Li, L.; Huang, W.; Qin, B.; Zhang, S. HEV ORF3 downregulatesCD14 and CD64 to impair macrophages phagocytosis through inhibiting JAK/STAT pathway. J. Med. Virol. 2019, 91, 1112-1119. [CrossRef]

51. Smith, P.D.; Shimamura, M.; Musgrove, L.C.; Dennis, E.A.; Bimczok, D.; Novak, L.; Ballestas, M.; Fenton, A.; Dandekar, S.; Britt, W.J.; et al. Cytomegalovirus enhances macrophage TLR expression and MyD88-mediated signal transduction to potentiate inducible inflammatory responses. J. Immunol. 2014, 193, 5604-5612. [CrossRef] [PubMed]

52. Stevenson, E.V.; Collins-McMillen, D.; Kim, J.H.; Cieply, S.J.; Bentz, G.L.; Yurochko, A.D. HCMV reprogramming of infected monocyte survival and differentiation: A Goldilocks phenomenon. Viruses 2014, 6, 782-807. [CrossRef] [PubMed]

53. Georgel, P.; Jiang, Z.; Kunz, S.; Janssen, E.; Mols, J.; Hoebe, K.; Bahram, S.; Oldstone, M.B.A.; Beutler, B. Vesicular stomatitis virus glycoprotein $\mathrm{G}$ activates a specific antiviral Toll-like receptor 4-dependent pathway. Virology 2007, 362, 304-313. [CrossRef] [PubMed]

54. Okumura, A.; Pitha, P.M.; Yoshimura, A.; Harty, R.N. Interaction between Ebola virus glycoprotein and host toll-like receptor 4 leads to induction of proinflammatory cytokines and SOCS1. J. Virol. 2010, 84, 27-33. [CrossRef] [PubMed]

55. Yamamoto, M.; Sato, S.; Hemmi, H.; Hoshino, K.; Kaisho, T.; Sanjo, H.; Takeuchi, O.; Sugiyama, M.; Okabe, M.; Takeda, K.; et al. Role of adaptor TRIF in the MyD88-independent toll-like receptor signaling pathway. Science 2003, 301, 640-643. [CrossRef] [PubMed]

56. Dunne, A.; O'Neill, L.A.J. Adaptor usage and Toll-like receptor signaling specificity. FEBS Lett. 2005, 579, 3330-3335. [CrossRef]

57. Lee, H.-K.; Dunzendorfer, S.; Soldau, K.; Tobias, P.S. Double-stranded RNA-mediated TLR3 activation is enhanced by CD14. Immunity 2006, 24, 153-163. [CrossRef]

58. Rajaiah, R.; Perkins, D.J.; Ireland, D.D.C.; Vogel, S.N. CD14 dependence of TLR4 endocytosis and TRIF signaling displays ligand specificity and is dissociable in endotoxin tolerance. Proc. Natl. Acad. Sci. USA 2015, 112, 8391-8396. [CrossRef]

59. Wu, D.; Sanin, D.E.; Everts, B.; Chen, Q.; Qiu, J.; Buck, M.D.; Patterson, A.; Smith, A.M.; Chang, C.-H.; Liu, Z.; et al. Type 1 Interferons Induce Changes in Core Metabolism that Are Critical for Immune Function. Immunity 2016, 44, 1325-1336. [CrossRef]

60. Martin, T.R.; Wurfel, M.M.; Zanoni, I.; Ulevitch, R. Targeting innate immunity by blocking CD14: Novel approach to control inflammation and organ dysfunction in COVID-19 illness. EBioMedicine 2020, 57, 102836. [CrossRef]

61. Jimenez-Duran, G.; Luque-Martin, R.; Patel, M.; Koppe, E.; Bernard, S.; Sharp, C.; Buchan, N.; Rea, C.; de Winther, M.P.J.; Turan, N.; et al. Pharmacological validation of targets regulating CD14 during macrophage differentiation. EBioMedicine 2020, 61, 103039. [CrossRef] [PubMed] 